\title{
Xanthogranulomatous hypophysitis: a different rare presentation in a young patient
}

Mohammad Ali Yaghoubi ${ }^{1}$, Samira Zabihian ${ }^{1}$, Amin Saeidinia ${ }^{1}$, Masoumeh Gharib ${ }^{1}$, and Ramin Ghiyasi Moghaddam ${ }^{1}$

${ }^{1}$ Mashhad University of Medical Sciences

December 13, 2021

\begin{abstract}
Hypophysitis is a rare inflammatory condition that may present both clinically and radiologically as a neoplastic lesion. Xanthogranulomas are rare intracranial lesions with controversial etiology. Here, we report a clinical case of histologically confirmed xanthogranuloma in a young female with type I diabetes mellitus and hypothyroidism.
\end{abstract}

\section{Hosted file}

CCR.doc available at https://authorea.com/users/450901/articles/549153-xanthogranulomatoushypophysitis-a-different-rare-presentation-in-a-young-patient 